\title{
METAFOROLOGIA E TEORIA DA NÃO CONCEITUALIDADE APLICADAS À HISTÓRIA DO DIREITO PENAL: O HIATO DE RACIONALIDADE NO DISCURSO CRIMINAL
}

\author{
METAPHOROLOGY AND THEORY OF NON-CONCEPTUALITY \\ APPLIED TO HISTORY OF CRIMINAL LAW: THE RACIONALITY \\ GAP IN CRIMINAL SPEECH
}

Hugo Leonardo Rodrigues Santos*

\begin{abstract}
RESUMO
Neste artigo pretende-se destacar a natureza metafórica do discurso jurídico-penal, por meio de uma análise crítica da pretensão de racionalidade no campo do direito. Para isso, são utilizadas a metaforologia e a teoria da não conceitualidade de Hans Blumenberg, como instrumentos heurísticos para a historicização de conceitos jurídicos, identificando-se seus elementos não racionalizáveis, consistentes em metáforas absolutas. Ao fim, exemplifica-se a utilidade desses preceitos teóricos, a partir do desvelamento de conceitos derivados das metáforas absolutas de livre-arbítrio e determinismo, no discurso criminal.
\end{abstract}

PALAVRAS-CHAVE: Metaforologia. História dos conceitos. História do Direito penal.

\begin{abstract}
This paper aims to highlight the metaphorical nature of the criminal law discourse, by means of a critical analysis of the rationality claim in the field of law. For this purpose, metaphorology and theory of nonconceptuality are used as heuristic devices for the historicizing of legal concepts, identifying their not racionalizable elements consistent in absolute metaphors. Finally, the work exemplifies the usefulness of these theoretical precepts, from the unveiling of concepts derived from absolute metaphors of free will and determinism, in criminal speech.
\end{abstract}

KEYWORDS: Metaphorology. Conceptual history. History of Criminal law.

Racionalidade a posteriori - Todas as coisas que vivem muito tempo embebemse gradativamente de razão, a tal ponto que sua origem na desrazão torna-se improvável. Quase toda história exata de uma gênese não soa paradoxal e ultrajante para o nosso sentimento? O bom historiador não contradiz, no fundo? ${ }^{1}$

Direito é metáfora e compreendê-lo importa ironia ${ }^{2}$.

A pretensão de racionalidade jurídica, tão característica da modernidade, esforça-se para esconder o fato de que as suas ideias e conceitos fundamentais tem a sua origem, invariavelmente, em mitos e crenças, em metáforas. $\mathrm{O}$ direito racional, portanto, disfarça os seus pés de barro - talvez, envergonhado da constatação de que toda a sua construção conceitual tem sua base de apoio fragilmente alicerçada sobre terreno movediço. Por óbvio que a admissibilidade

\footnotetext{
* $\quad$ Doutor e mestre em Direito Penal pela Universidade Federal de Pernambuco - UFPE. Professor de Direito Penal e Criminologia na Universidade Federal de Alagoas - UFAL.

E-mail: hugoleosantos@yahoo.com.br.

1 NIETZSCHE, 2004, p. 15.

2 LIMA, 2013b, p. 9.
} 
dessa vulnerabilidade, por parte da autolegitimada razão, poderia colocar em xeque a própria legitimidade do direito. Por esse motivo, Alexandre da Maia afirmou que o projeto iluminista, referenciado pelo binômio racional/irracional, terminou por hipostasiar certas visões sobre o direito 3 . Prosseguindo com esse raciocínio, desvelar essas facetas ocultas do pensamento jurídico - a sua metade dionisíaca - equivaleria a cumprir com uma função extremamente importante, lembrando-nos da carência de segurança epistemológica do conhecimento, no campo do direito. Assim, exatamente por esse motivo, não podemos esquecer "dos eclipes, que nos mostram a tensão paradoxal entre luz e sombra, entre razão e crença, entre o certo e o errado, entre o direito e o não-direito"4.

A natureza metafórica do discurso jurídico fica evidente, logo de início, ao observarmos a celeuma acerca da conceituação da própria ideia de direito. Como se trata de uma premissa fundamental para a estruturação do saber jurídico - definir, afinal de contas, o que é o direito -, um incauto poderia crer, inocentemente, que nada mais há de fértil, no terreno dessa indagação. Contudo, estaria sendo precipitado, para dizer o mínimo. Isso, porque, de tudo o que se falou sobre o complexo tema, de toda a construção teórica existente a esse respeito, pode-se concluir que o que se tem em mãos corresponde a apenas um vislumbre, demasiado impreciso, do que seria o direito. Talvez, por isso mesmo, seja mais simples e funcional responder à indagação pragmática de qual direito seria aplicado - quid juris? -, em uma situação concreta, que tentar responder ao persistente enigma, relacionado ao que é, de fato, o direito. Muito provavelmente, a imprecisão das concepções acerca do direito, seja uma característica incontornável, uma verdadeira aporia que impossibilitaria uma definição mais objetiva do que seja o fenômeno jurídico. Conforme Herbert Hart ensinou, o que os teóricos disseram sobre o direito, por certo, possibilitou uma maior compreensão do mesmo. Entretanto, "tais afirmações são ao mesmo tempo esclarecedoras e causadoras de perplexidades: assemelham-se mais a grandes exageros de algumas verdades sobre o direito indevidamente esquecidas, do que a definições serenas" .

Nesse sentido, o discurso jurídico é essencialmente metafórico, justamente por trabalhar com juízos que se aproximam mais da estética que da lógica, utilizando-se de analogias abertas e aproximativas, afastando-se de categorizações e identidades. O tema da correlação entre metáfora e direito é de enorme complexidade, e está longe de nossas pretensões adentrarmo-nos nos seus pormenores ${ }^{6}$. Entretanto, devemos indicar as repercussões da metafórica no discurso jurídico, para os fins específicos da historicização dos seus conceitos.

3 DA MAIA, 2011, p. 166.

4 DA MAIA, 2011, p. 167.

5 HART, 2007, p. 6.

6 Para um maior aprofundamento: LIMA, 2013b. CASTRO JR., 2009. 
Isso, porque a metaforologia consiste em uma espécie de complemento à história dos conceitos alemã, modulando um pouco seu otimismo racionalista. À temporalização dos conceitos, propugnada pela Begriffsgeschichte, e sobretudo às categorias heurísticas que lhes são próprias, tal campo de estudos propugna zonas de não conceitualidade no pensamento, sendo capaz de demonstrar o que resta de mítico e metafórico na razão jurídica, e de pôr dúvidas consistentes em seus pretensiosos fundamentos racionais. Nosso objetivo, portanto, seria demonstrar a impossibilidade de se analisar historicamente certas ideias, caso não sejam observadas as suas bases, as quais não são diretamente apreensíveis logicamente, por meio da razão, por tratar-se na verdade de metáforas absolutas.

Cumpre indicar algumas premissas para o tratamento do assunto. Inicialmente, é preciso alertar para o fato de que as metáforas estão vinculadas à retórica ${ }^{7}$. Ora, essa disciplina sempre foi vista com desconfiança, na história da filosofia e do pensamento, em razão de ter perdido a disputa com os ideais do platonismo, que terminaram sedimentados nas profundidades ocultas das mentalidades. A filosofia platônica desdenhava abertamente dos sofistas, imputando-lhes atributos pouco nobres, como os de falseadores da verdade e trapaceiros. Contudo, apesar de toda essa tradição filosófica, que deixou a retórica em segundo plano, pode-se perceber que a importância, para o pensamento, da criatividade e da arte, do impreciso e inexato, vem sendo reconhecida, mais uma vez, sendo possível afirmar essa mudança de concepção da retórica como um sintoma do reposicionamento da metáfora ${ }^{8}$.

Nesse movimento, a retórica passa a ser entendida como algo naturalizado na própria linguagem, especialmente a jurídica. Por isso, as metáforas passam a constituir-se como um liame necessário, entre a formação da linguagem e o processo de conhecimento, "seriam a base comum que uniria o cognitivo e o linguístico" ". Não há nenhuma contradição em se falar em retórica, nos domínios da história. A narratividade sempre está presente, no trabalho do historiador, sendo por isso impossível eliminar uma carga de subjetividade ou mesmo criatividade - das suas interpretações, que são o próprio objeto da historiografia. Tampouco a retórica significaria, necessariamente, uma atitude de adesão radical e incondicional à linguagem, no sentido de se entender à história, tão somente, como puro discurso, sem nenhum vínculo com a observação da realidade extralinguística. Como sabido, essa foi a opinião de Michel Foucault ${ }^{10}$, em suas primeiras obras, e de Hans-Georg Gadamer ${ }^{11}$, contra as quais poderiam

7 CASTRO JR., 2009, p. 68.

8 LIMA, 2013, p. 33.

9 CASTRO JR., 2009, p. 96.

10 FOUCAULT, 1969.

11 GADAMER, Hans-Georg. Teoria da história e linguagem: uma réplica de Hans-Georg Gadamer. KOSELLECK, Reinhart. Estratos do tempo: estudos sobre história. Rio de Janeiro: 
ser colocadas as posições do próprio Michel Foucault, em um estágio mais maduro de seus trabalhos ${ }^{12}$, e de Reinhart Koselleck ${ }^{13}$. Entendemos, portanto, que é possível reconhecer o papel essencial da linguagem, na formação do conhecimento histórico, sem acreditar que ele resumiria toda a realidade apreensível. Com isso, voltamos à velha e debatida aporia da linguagem, pois apesar de sabermos que existem fatos extralinguísticos, o conhecimento a respeito deles somente poderia ser construído através de processos linguísticos.

Não obstante, a retórica aplicada à história dos conceitos também pode ser interpretada como um repúdio veemente às concepções ontológicas da verdade, ou à posição de que os conceitos atingiriam sua essência, quando representassem com perfeição os dados da realidade que lhes seria cabível. Em outras palavras, a retórica consiste em uma indisponível postura cética, com relação a verdades imutáveis, fazendo crer que as estruturas históricas e linguísticas são condições de produção da verdade, e não meras contingências de sua percepção. Essa posição de ceticismo pode ser bem percebida na obra de Friedrich Nietzsche. Segundo o filósofo alemão, a verdade seria "uma multidão móvel de metáforas, metonímias e antropomorfismos; em resumo, uma soma de relações humanas que foram realçadas, transpostas e ornamentadas pela poesia e pela retórica e que, depois de um longo uso, pareceram estáveis, canônicas e obrigatórias aos olhos de um povo: as verdades são ilusões das quais se esqueceu que são, metáforas gastas que perderam sua força sensivel, moeda que perdeu sua efígie e que não é considerada mais como tal, mas apenas como metal" ${ }^{14}$. Tal concepção vai ao encontro do estudo histórico dos conceitos, tanto na vertente propugnada por Michel Foucault - que acreditava que as práticas e o exercício do poder moldam os saberes, constituindo as verdades históricas ${ }^{15}$ -, como também na versão da Begriffsgeschichte, de Reinhart Koselleck - que apontava para a contextualização histórica da semântica dos conceitos, que é temporal, e absolutamente conectada à história social ${ }^{16}$.

De toda forma, e é esse o ponto que nos interessa, a realidade só é cognoscível linguisticamente, e as metáforas compõe a estrutura das linguagens - inclusive as ditas científicas. A consequência disso é que o conhecimento, construído em torno da linguagem, apresenta seus mitos e espíritos, sua dose amarga de irracionalidade. As pretensões de fixação de verdades ontológicas são perturbadas por atributos da própria linguagem, o que torna impossível a definição cabal de conteúdos semânticos. Nesse sentido, pode-se perceber

Contraponto, 2014.

12 FOUCAULT, 1975 e 2013.

13 KOSELLECK, 2006, p. 103.

14 NIETZSCHE, 2001, p. 12-13, grifamos no final.

15 FOUCAULT, 2005.

16 KOSELLECK, 2006. 
uma "utilização indiscriminada de palavras e, por conseguinte, de formas de pensamento que buscam muito mais legitimar o poder conferido do que criar uma ideia de conteúdo ao conhecimento"17. Desse modo, a definição do significado dos termos jurídicos atende a critérios pragmáticos, vez que o sentido das expressões não está pré-fixado, considerando que resultam de um processo linguístico de construção semântica ${ }^{18}$. Assim, não se pode abrir mão de observar com atenção as contingências extralinguísticas, de ordem social ou político-econômica, com a finalidade de compreender o sentido pragmático dos termos jurídicos.

Existe literatura farta sobre esse tema, fazendo-nos perceber, por exemplo, que a metáfora seria "o vínculo intelectual entre a linguagem e o mito"19. Mesmo no campo especificamente jurídico, já foram apontadas essas aproximações, entre o discurso do direito e a metafórica. Nesse sentido, Alf Ross afirmou que se faz necessário admitir que "nossa terminologia e nossas ideias apresentam uma considerável semelhança estrutural com o pensamento mágico primitivo, com respeito à invocação de potências sobrenaturais, as quais, por sua vez, são convertidas em efeitos fáticos. Não podemos descartar a possibilidade de que tal semelhança esteja enraizada numa tradição que, ligada à linguagem e ao poder que esta tem sobre o pensamento, constitui um velho legado de infância de nossa civilização" ${ }^{20}$.

Para não fugir aos propósitos apresentados, e como seria impossível abarcar todos os estudos existentes sobre as consequências da utilização das metáforas nos discursos, iremos focar a nossa análise nas concepções de metaforologia e teoria da não conceitualidade, a partir da obra do filósofo alemão Hans Blumenberg. Faremos isso, dentro dos objetivos propostos, focando a demonstração das metáforas na linguagem jurídica, com ênfase no discurso próprio do campo criminal. Cumpre, inicialmente, mencionar os pressupostos teóricos, adotados pelo autor. Basicamente, a metaforologia resultaria de uma discordância parcial com a tese da secularização das ideias - mundanização -, que seria uma das principais consequências do processo de modernização, compreendido no conceito weberiano de desencantamento do mundo ${ }^{21}$. Como sabido, essa teoria é a base para a Begriffsgeschichte de Reinhart Koselleck, que defende a ideia de uma aceleração do tempo, em decorrência das transformações conceituais advindas da modernidade. Entretanto, Hans Blumenberg tem algumas ressalvas quanto a essa posição, discordando da visão otimista de racionalidade, implícita nesse pensamento.

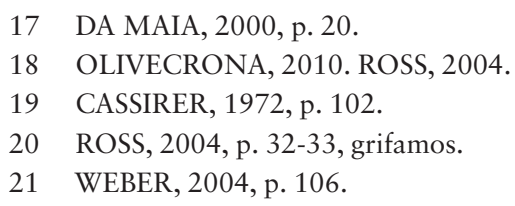


Segundo a ideia corrente de secularização, toda a estrutura teológica do pensamento, típica das sociedades anteriores ao Século XVIII, teria se transformado, a partir da revaloração dos ideais mágicos e místicos, por meio de uma racionalidade humana, demasiado humana. Essa concepção foi muito importante, em vários campos do conhecimento, principalmente por influência da sociologia weberiana. No pensamento político, por exemplo, o entendimento é de que toda a formação do Estado moderno, os sistemas de governo, a burocracia governamental, refletiriam ideais teológicos mundanizados. Nesse sentido, Carl Schmitt chegou a afirmar que a estrutura do Estado moderno é baseada em conceitos teológicos secularizados ${ }^{22}$.

Tomando-se por base essas premissas, a própria ideia moderna de história (Geschichte) também teria por fundamento o desapego moderno à teologia cristã. Conforme Karl Lowith ensinou, a filosofia da história seria fruto de uma secularização de premissas religiosas, de seu abandono. A fé no progresso histórico, desse modo, seria a última religião ${ }^{23}$. O abandono da escatologia cristã realçaria, por sua vez, a aporia do regime de historicidade contemporâneo, demasiadamente acelerado por um horizonte de expectativas que se faz presente, um presentismo ${ }^{24}$, em razão da negativa de construção de um sentido para a história. Assim, "a impossibilidade de elaborar um sistema progressivo de história secular na base religiosa da fé tem a sua contrapartida na impossibilidade de estabelecer um plano significativo da história através da razão. Isto é corroborado pelo senso comum, pois quem ousaria proferir uma afirmação concreta sobre o objetivo e o sentido de acontecimentos contemporâneos?" 25 .

Como já dito, Hans Blumenberg discorda dessa interpretação, acreditando que a modernidade não se desvencilhou completamente de seus mitos, não teria atingido uma racionalidade técnica absoluta, na qual a abstração e a incerteza estariam ausentes. Pelo contrário, conforme preleciona, a dissolução da metafísica, decorrente do afastamento do pensamento teológico, teria dado azo à metaforologia, na linguagem ${ }^{26}$. Segundo o autor, o conceito de secularização tornou-se corrente, na teoria social, e por isso foram abandonados os necessários questionamentos sobre sua validade, enquanto critério de explicação da modernidade. A partir de fórmulas simplistas, todos os fundamentos modernos teriam sua origem em princípios teológicos cristãos, a igualdade apregoada pelo iluminismo, a ideia de um legislador detentor de autoritas, entre outros. Sua postura era de ceticismo: não duvidava, absolutamente, da existência

22 SCHMITT, 2006, p. 35.

23 LÖWITH, 1991, p. 194.

24 HARTOG, 2010, p. 158.

25 LÖWITH, 1991, p. 198.

26 BLUMENBERG, 2010, p. 132. 
concreta do processo de secularização, em determinados contextos, mas tentava chamar a atenção para a normatização da ideia de secularização, decorrente da desistência de se tentar comprovar isso faticamente, problematizando o uso de tal ideia como uma explicação apriorística. Nesse sentido, afirmou que "é perfeitamente possível - e, de fato, é provavelmente a causa - que o conceito de secularização tenha sido introduzido com um sentido puramente descritivo, e apenas ocasionalmente tenha sido suplementado por uma referência à expropriação política de deuses eclesiásticos. Eu apenas acredito que posso observar que essa associação histórica impulsionou o desenvolvimento de um aumento da precisão, referente à utilização do termo, em determinada direção. E eu não penso que isso tenha sido acidental" 27 .

Por isso, a modernidade - ou a sua explicação - baseia-se em uma impressão vaga, não acabada, uma referência frágil que sempre escapa por entre os dedos do observador. A metáfora da secularização - chave heurística para a fixação do sentido de progresso, adotado pela filosofia da história - desafia todo o otimismo porventura existente, com relação à racionalidade moderna. Qualquer definição fundamental, adotada na interpretação da sociedade, teria como pressuposto uma metáfora. Conforme constatou, “a investigação da história conceitual de secularização aparentemente trouxe à luz um resultado contraditório: de um lado, dissecou um processo que se encaminhou para uma nominalização, um processo direcionado para a remoção de qualquer ambiguidade de conteúdo conceitual, e assim rumo a uma definição metódica, enquanto que, de outro lado, descreve as últimas fases desse processo como caracterizadas por uma utilização metafórica. Contudo, não é o uso que é metafórico, mas sim a orientação do processo de formação do conceito" ${ }^{28}$.

Caso se persistisse com uma explicação da modernidade baseada exclusivamente na secularização - ideia absolutamente frágil, como já explicado - a conclusão inexorável seria a de sua ilegitimidade. Entretanto, não é esse o entendimento de Hans Blumenberg. Segundo o autor, seria necessário buscar outros fundamentos para a modernidade, afastados da ideia de uma mundanização do pensamento religioso. Novas descobertas científicas - como, por exemplo, a concepção do infinito - criaram sérias dúvidas, sobre a validade de estruturas escatológicas, derivadas do cristianismo. O progresso, entre outras características definidoras do novo tempo, seriam fruto de uma nova forma de pensamento, que incluiria a consideração da estética, da arte. De certo modo, Friedrich Nietzsche já havia prenunciado essa nova explicação para a modernidade, ao afirmar que a existência do mundo só se justifica como

27 BLUMENBERG, 1999, p. 18.

28 BLUMENBERG, 1999, p. 22, grifamos por último. 
fenômeno estético ${ }^{29}$. Por isso, a lógica religiosa secularizada não seria capaz de oferecer elementos de compreensão da modernidade, que teria sua legitimidade a partir de outros fundamentos ${ }^{30}$. Nesse contexto, a compreensão do papel das metáforas no pensamento é fundamental.

Para compreender isso, inicialmente falaremos sobre o significado do conceito. Hans Blumenberg entende que o conceito é um produto da razão, apesar de não haver identidade entre ambos. $\mathrm{O}$ autor defende a possibilidade de uma teoria antropológica do conceito, que explicaria como o pensamento humano começou a conceber os conceitos. Nesse sentido, a necessidade de antecipar possíveis eventos, com a finalidade de prevenção, fez com que o homem agisse remotamente, conceituando a realidade. O actio per distans, portanto, motivou a criação de signos que representariam possíveis ocorrências futuras. A armadilha, para o homem primitivo, seria o modelo perfeito de uma expectativa materializada, o primeiro triunfo do conceito: com vistas a capturar um animal determinado, fez-se a previsão necessária para antecipar uma ocorrência futura ${ }^{31}$.

O conceito deve conter um grau de indeterminação, para dar conta de expectativas relacionadas a eventos e objetos futuros e incertos. Mas, por outro lado, também deve possuir clareza suficiente para excluir aqueles objetos que não serão submetidos a sua classificação $0^{32}$. Em todo caso, "o conceito deve ser, em princípio, definível, mesmo se, em uma situação dada, ninguém seja capaz de satisfazer as exigências postas pela definição. A racionalidade não começa com o preenchimento de determinadas exigências senão com que elas sejam reconhecidas" ${ }^{33}$. A situação de indeterminação, decorrente da utilização de um conceito, possibilita ligar o pensamento, automaticamente, a uma percepção. Tal comando automático normatiza a reação, decorrente da antecipação do evento ou objeto, mas depende de que outros tenham o conceito, pauta-se por um questionamento acerca da situação. Contudo, existem percepções que não estão acompanhadas de juízos ou conceitos, que permanecem desvinculadas de uma referência racionalizada. De modo que se poderia falar em uma relação entre o conceito e a não conceitualidade, zonas de percepções desacompanhadas de uma racionalização ${ }^{34}$.

Segundo Nelson Saldanha, a compreensão da metáfora se situaria entre a noção de analogia e o conceito de juízo, elaborado por Immanuel Kant ${ }^{35}$.

$\begin{array}{ll}29 & \text { NIETZSCHE, 1999, p. } 18 . \\ 30 & \text { BLUMENBERG, 1999. } \\ 31 & \text { BLUMENBERG, 2013, p. } 49 . \\ 32 & \text { BLUMENBERG, 2013, p. } 47 . \\ 33 & \text { BLUMENBERG, 2013, p. } 73 . \\ 34 & \text { BLUMENBERG, 2013, p. } 72 . \\ 35 & \text { SALDANHA, 2002, p. } 39 .\end{array}$


Este filósofo alemão desenvolveu a sua obra filosófica partindo da constatação de que a razão se sente constantemente embaraçada, quanto tem pretensões de formular explicações sobre determinados objetos. Por isso, propôs uma inversão metodológica, uma revolução copernicana na filosofia, devendo o conhecimento regular-se por juízos a priori, que são as condições para a cognoscibilidade humana, e não mais o contrário, como costumava ser feito ${ }^{36}$. Acontece que não se pode, na construção do conhecimento, ultrapassar os limites da experiência possivel, o que termina por impor linhas demarcatórias, para aquilo que poderia ser submetido a uma conceitualização, por meio da racionalização. Não obstante, mesmo que não se possa conceituar algo, quando sua cognoscibilidade ultrapassa as limitações humanas para a experimentação, ainda se pode pensar a respeito disso, com base em representações ${ }^{37}$. O exemplo utilizado pelo filósofo é importante para o campo penal. Segundo Immanuel Kant, não se pode conceituar a liberdade, contudo, essa ideia pode ser perfeitamente utilizada para juízos morais, por meio de representações, servindo como fundamento da razão prática. $\mathrm{O}$ fato de a liberdade se situar em uma zona de não conceitualidade não inviabiliza a consideração desse dado, por meio de aproximações, de metáforas. Por isso, o paradoxo genial do filósofo consiste, exatamente, em vincular a razão prática à frustração da razão pura: não se pode admitir a liberdade sem abrir mão de compreendê-la por meio de uma razão especulativa ${ }^{38}$.

Justamente nesse contexto, justifica-se a metáfora. Ela viabiliza o pensamento, exatamente onde a razão especulativa não é admissível, nos hiatos, onde não são cabíveis os conceitos. Serve como uma ponte de ligação, entre as zonas de conceitualização e não conceitualização. Essas categorias não possuem um significado referencial, pois "não apontam diretamente para nada" ${ }^{39}$. Dessa característica, temos uma função pragmática da metáfora, uma regra de reflexão, pois o seu valor, para o utente, não decorre do significado delas próprias - já que são palavras ocas ${ }^{40}$-, mas sim da finalidade prática que as ideias que podem ser relacionadas à metáfora podem possuir, do seu propósito pragmático ${ }^{41}$. Assim, "as metáforas deixam espaços em branco, em termos de enunciação. Compreender isso permite compreender muito em relação à dinâmica da interpretação. As figuras metafóricas definitivamente compõem aspectos estéticos do falar, mas têm importância bem maior que simples rebuscamentos" ${ }^{42}$. Portanto, para entende-las, seria necessário pensar em uma relação de sua literalidade - de

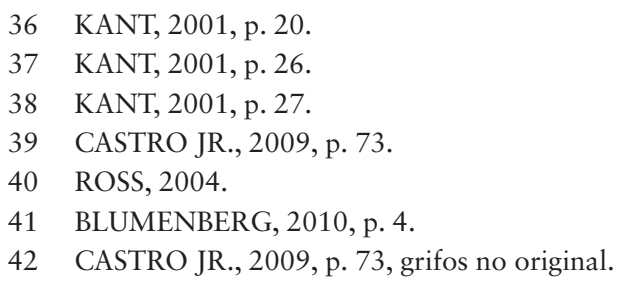


todo imprecisa e indeterminada - com sua extraliteralidade, o que está fora de uma apreensão objetiva por meio do texto ${ }^{43}$.

É interessante realçar a importância das metáforas, no direito. As metáforas deixam mais clara a função da criatividade ${ }^{44}$, no discurso jurídico, destacando a existência de uma relação entre logos e imaginação ${ }^{45}$. Nesse caso, a criatividade não significaria tão-somente o motor de uma transformação do pensamento, em direção a uma conceitualização, sendo na verdade algo mais abrangente, que termina por impulsionar uma contínua renovação dos conceitos em si mesmos, uma mutação de seus significados, além da criação de mais conceitos, todos conectados pela imagem fluída, proporcionada pela metáfora. Além do mais, as metáforas trabalham com dados implícitos, que forçam a imaginação do utente para a interpretação dos signos, chegando-se a informações que não estão disponíveis objetivamente. Por isso, "metaforizar consiste em dizer algo por implicitação (...) Há uma relação de analogia, de partilhada estrutura, entre as coisas contrapostas pela metáfora" ${ }^{46}$.

Diante dessas constatações, é possível emendar que a metáfora é mais que acidental, no discurso jurídico, sendo na verdade um elemento próprio do direito, um de seus pilares de sustentáculo. Afirmar isso, sem sombra de dúvidas, pode gerar uma certa insegurança naqueles juristas mais românticos, que ignoram solenemente os questionamentos mais profundos acerca da natureza do saber que lhes serve de mister. Tal sentimento paralisante seria decorrente das dúvidas que tal postura cética faz surgir - que, como um veneno de efeito lento, corrói paulatinamente a crença cândida no tão propalado racionalismo do pensamento jurídico ${ }^{47}$. Entretanto, não se pode negar essa característica dúbia da linguagem do direito. Como bem lembrou Pedro Parini, não seria possível ignorar o fato mais que evidente de que há "um mundo inteiramente fantástico (metafórico) e mágico-ritualístico do direito que nós herdamos e sobre o qual raramente refletimos criticamente" 48 . A ideia de uma literalidade do texto jurídico - da lei -, bem como da sua organização sistemática, também são metáforas bastante presentes na cultura jurídica ${ }^{49}$. Não é uma coincidência,

\footnotetext{
43 CASTRO JR., 2009, p. 75.

44 SALDANHA, 2002.

45 BLUMENBERG, 2010, p. 4.

46 CASTRO JR., 2009, p. 73-74.

47 Talvez, essa metáfora seja melhor empregada com a utilização do termo grego phármakon, que quer dizer, a um só tempo, o remédio e o veneno. Isso porque, ao mesmo tempo que a metaforologia poderia destruir o ídolo tão cultuado do racionalismo jurídico - sendo, portanto, veneno -, por outro lado, é uma ferramenta heurística poderosa, para desvencilhar o direito da inocência de um pensamento cartesiano, deixando-o à salvo das ilusões febris do dogmatismo estéril - e, nesse sentido, a compreensão da função das metáforas jurídicas é um remédio (DERRIDA, 2005).

48 LIMA, 2013b, p. 105.

49 CASTRO JR., 2009, p. 75-82 e 88-91.
} 
portanto, que algumas escolas de interpretação foram construídas em torno dessas visões metafóricas do direito.

Hans Blumenberg explicou que o discurso cartesiano, extremamente otimista, no que diz respeito à racionalidade, propunha uma objetificação do mundo, que se daria através de terminologias, utilizadas com a função de capturar com precisão os fenômenos, por meio de conceitos bem definidos. Ora, se isso fosse, de fato, possível, a própria história dos conceitos se tornaria inútil, pois não haveria nenhum sentido em se perder um tempo precioso compreendendo a formação conceitual, após termos chegado à definitiva forma do conceito, quando então ele representaria, com perfeição, o objeto a que corresponde ${ }^{50}$. Contudo, esse ideal naïve de racionalidade não é atingível, em absoluto, e por isso várias categorias do pensamento não são passíveis de definições precisas, sendo avessas a uma conceitualização. Nesses casos, para dar conta da referência a tais categorias, adota-se o recurso - muito comum na linguagem jurídica - correspondente à utilização de metáforas, que são vislumbres indiretos da coisa em si, trabalhando com base na analogia, na aparência, sob a forma de juízos estéticos. Com esse significado, as metáforas podem ser verdadeiros elementos fundantes da linguagem jurídica, os quais resistem a serem, de todo, absorvidos racionalmente, não sendo compatíveis com uma formalização lógica do pensamento ${ }^{51}$. Partindo do princípio de que essas metáforas estão presentes na linguagem jurídica, poderíamos parafrasear Hans Blumenberg, afirmando que a meta essencial da história conceitual - vista sob uma concepção mais larga - seria, também, compreender essa função de impossibilidade de conceitualização, essa incapacidade de a linguagem jurídica ser absolutamente estruturada, a partir de conceitualizações ${ }^{52}$.

Segundo Hans Blumenberg, existiriam certas metáforas absolutas, que constituiriam verdadeiros limites à racionalização por meio de conceitos. Utilizando a terminologia kantiana, tais estruturas seriam comprovações das limitações da experiência, fronteiras além das quais seria inviável a utilização de uma razão especulativa. Avessas à objetificação conceitual, são as unidades mínimas, os átomos do pensamento. Como explicou o autor, o fato de as metáforas serem absolutas "significa apenas que resistem à exigência terminológica, que não possam ser absorvidas pela conceitualidade, que uma metáfora não possa ser substituída por outra, representada ou corrigida por uma mais precisa" ${ }^{53}$. Diante de tais elementos, teríamos uma necessidade incontornável de nos

50 BLUMENBERG, 2010, p. 2.

51 BLUMENBERG, 2010, p. 3.

52 BLUMENBERG, 2010, p. 3-4.

53 BLUMENBERG, 2010, p. 5, grifamos. 
valermos de conceitos paralelos, de significados que se encontram em outras partes, porque, em si mesmo, elas não dizem nada. Isso, porque as metáforas absolutas apresentam uma insuperável resistência ao contexto ${ }^{54}$.

O autor dá vários exemplos, em sua obra, de metáforas absolutas. Por exemplo, a metáfora da verdade, do seu poder de autoimposição, decorrente da versão imagética da verdade como iluminação. Nesse sentido, não é possível uma conceituação da verdade, que seria somente a maneira de denominar a qualidade que possuem certas representações, as quais prevalecem sobre outras, por possuírem um status de críveis ${ }^{55}$. Conforme já indicado, segundo Friedrich Nietszche a verdade seria somente um conjunto de metáforas desgastadas ${ }^{56}$. Não obstante, no processo de objetificação - desencantamento - do mundo, a verdade foi afastada de sua natureza essencialmente metafórica, vista como algo acabado, independentemente do contexto. "Foi tomada na sua palavra, naturalizada, e tornada indistinguível de uma proposição física" ${ }^{57}$. Contra essa visão ontológica de verdade, é possível contrapor uma historicização: a verdade vista como um processo histórico, a história de seu conceito, sua genealogia. Outra dessas metáforas absolutas, referidas pelo filósofo alemão, diz respeito à totalidade do mundo. A ideia grega de cosmo já significou uma tentativa de representação da pluralidade dos mundos, a partir de uma só denominação. Logicamente que isso não seria possível, caso se esperasse uma definição precisa, um conceito, e por isso a indeterminação do termo assume o papel de uma metáfora. Nesse sentido, "é decisivo que esse único substantivo assuma o lugar da incapacidade dos gregos em designar a totalidade do universo com uma só palavra" ${ }^{58}$. Com isso, torna-se possível utilizar o singular mundo, para designar a indeterminação contida no plural mundos. Essa metáfora fica bem nítida na expressão famosa de Ludwig Wittgenstein, de que o mundo é tudo o que acontece $e^{59}$.

A importância da metaforologia reside, justamente, na possibilidade de criticar o apego à racionalidade, desvelando o que há de mítico e metafórico nas estruturas do pensamento. Contudo, é possível tecer algumas críticas à teoria de Hans Blumenberg. Uma delas diz respeito à aplicabilidade restrita do estudo, uma certa limitação, contida na sua filosofia. Conforme preleciona Felix Heidenreich, a teoria da não conceitualidade e a metaforologia seriam uma decorrência do que se convencionou como filosofia da subjetividade, e não chegaram a constituir uma teoria política. O que não deixa de ser inusitado, pois o destaque que deu ao papel dos mitos e metáforas, na significação do

54 BLUMENBERG, 2013, p. 113.

55 BLUMENBERG, 2010, p. 11-12.

56 NIETZSCHE, 2001, p. 12-13.

57 BLUMENBERG, 2010, p. 12.

58 BLUMENBERG, 2013, p. 118.

59 WITTGENSTEIN, 1993, p. 33. 
mundo, poderia ter se transformado em uma preocupação mais generalizada, considerando que a autoafirmação humana sempre é um projeto comum, de conteúdo político ${ }^{60}$. Ao invés disso, permaneceu resumido ao domínio da estética, da arte, pois o autor não frisou as consequências desse método para os aspectos sociopolíticos.

Por exemplo, descuidou inteiramente do direito, ao contrário de pensadores que lhe foram contemporâneos, como Jürgen Habermas. Segundo Felix Heidenreich, é "surpreendente que a questão do direito nunca tenha sido realmente discutida por Blumenberg. Partindo de um ponto de vista hegeliano, o direito é o mais óbvio exemplo do que ele chama de espírito objetivo (objektiver Geist), ferramentas culturais comuns tomando a forma de coisas naturais, com existência indiscutível" ${ }^{61}$. O direito é, como explicado acima, inteiramente construído e produzido tomando por base metáforas e mitos, muito embora não se resuma neles, considerando que sua existência não depende, simplesmente, de acreditarmos ou não nesses construtos simbólicos. Por isso, o direito torna-se real, assim como seus conceitos, tendo consequências vivas na realidade social, e dando origem a práticas e instituições. Por essa razão, a ausência de uma preocupação com o direito, entre outros aspectos políticos, é uma carência gravemente sentida, na metaforologia de Hans Blumenberg.

Acreditamos que essa lacuna pode ser perfeitamente suprida, pois é possível a utilização da metaforologia, como ponto de partida de uma análise do pensamento jurídico. Mais que isso, ousamos afirmar que a compreensão das metáforas absolutas seria um complemento e, também, um catalisador para a aplicação da Begriffsgeschichte, de Reinhart Koselleck, ou até mesmo da arqueogenealogia de Michel Foucault, no domínio do direito. Para compreender essa posição, é necessário lembrar que a opção por uma perspectiva retórica do direito implica na concepção de que os seus fundamentos não são estáticos, de que os conceitos jurídicos são contingenciais, os quais estão sempre se modificando, em função da abstração dos seus postulados metafóricos. No mais, as metáforas absolutas também possuem historicidade. Segundo Hans Blumenberg, a história das metáforas teria um sentido ainda mais radical que a dos conceitos, "porque a transformação histórica de uma metáfora lança luz sobre a dinâmica dos horizontes históricos de significado e modos de compreensão, dentro dos quais sofreram suas modificações" ${ }^{62}$.

Isso significa que a compreensão da história das metáforas facilita a percepção das alterações conceituais, tendo em vista que os conceitos têm como fundamentos as metáforas absolutas. Assim, a não conceitualidade

60 HEIDENREICH, 2015, p. 537.

61 HEIDENREICH, 2015, p. 537.

62 BLUMENBERG, 2010, p. 5. 
coloca-se a serviço da conceitualidade ${ }^{63}$, criando as condições para esta última, determinando seus horizontes. Quanto mais próximo de uma conceitualização precisa a linguagem conseguir chegar, menos necessária será a utilização das metáforas. Contudo, isso também significa que a linguagem jurídica sempre será, em certa medida, metafórica - pois a indeterminação e imprecisão estarão sempre presentes - e, por isso, invariavelmente haverá uma região de não conceitualidade, nesse domínio. Por isso, os conceitos jurídicos são estruturados em torno de metáforas absolutas, como as ideias de igualdade e equidade jurídica ${ }^{64}$, justiça, proporcionalidade, liberdade, entre outros fundamentos basilares, todos de fundo metafórico, impassíveis de serem conceituados. Ao longo da história, esses conceitos são transformados, modificados, mas as metáforas absolutas continuam a lhes servir de balisa, além de fundamentarem o surgimento de novos conceitos.

As metáforas perduram, exatamente, por serem incrivelmente plásticas, porque não possuem conteúdo semântico imediato, sendo formadas por uma indeterminação de significado. Isso não equivale a uma perpetuidade das metáforas, ou seja, que elas seguiriam, necessariamente, um continuísmo histórico. Muito pelo contrário, são comuns as rupturas, já que o significado das metáforas é obtido indiretamente, por um reflexo, tomando-se como referência o entendimento dos conceitos, que lhes são relacionados. E, como se sabe, os conceitos jurídicos são voláteis. No mais, as metáforas também podem morrer, o que aconteceria quando são deturpadas pela literalidade, quando sua indeterminação é reduzida por um significado imediato e único. Segundo Torquato Castro Júnior, isso aconteceria com frequência ${ }^{65}$. De todo o exposto, poderíamos resumir a relação entre as metáforas e conceitos, no campo do direito, a partir de outra metáfora, já referida acima. Se a verdade, de fato, fosse uma luz, a iluminar o conhecimento, seria possível afirmar que a frágil claridade das ideias jurídicas seria semelhante a um fogo-fátuo: seus significados, construídos retoricamente, são tão fulgazes, que antes de nos acostumarmos com a sua luminosidade, novas mudanças conceituais nos devolveriam às penumbras da incerteza.

Após essas explicações, cumpre indicar qual seria a função da metaforologia, para a história do discurso jurídico-penal, como poderia ser utilizada essa teoria no domínio do direito criminal. Faremos isso por meio de um exemplo-chave, que pode servir como Norte para a compreensão de toda a discussão jurídico-penal moderna: a tensão entre os postulados de determinismo e livre-arbítrio, enquanto justificadores da responsabilidade penal.

63 BLUMENBERG, 2013, p. 95.

64 LIMA, 2013b, p. 105.

65 CASTRO JR., 2009, p. 71. 
De antemão, cumpre lembrar que, em razão do excesso de categorias relacionadas à subjetividade, tão características desse ramo do direito, já teríamos uma presença marcante das metafóras. Exatamente por lançar mão de ideias fundamentais, situadas em uma zona de não conceitualidade - tais como consciência, liberdade de agir, determinismo, vontade, entre muitas outras metáforas absolutas, frequentes no direito penal -, podemos dizer que a metaforologia é necessária, para a compreensão do pensamento jurídico-penal. Muitos dos conceitos desenvolvidos pela doutrina criminal são tentativas de lidar com esses dados, inexplicáveis por meio de uma conceituação precisa, servindo tais metáforas como uma referência - ainda que maleável - para a aplicação da norma penal.

Assim, é possível uma outra explicação, para a velha disputa entre os fundamentos basilares das Escolas clássica e positivista, cenário para tantas afirmações passionais dos doutrinadores. Como já dito, há ressalvas importantes a essa dualidade no pensamento penal, entre clássicos e positivistas, mas mesmo sabendo-se da inexistência de um corpo homogêneo de predicados penais, em cada um dos lados da contenda, é preciso compreender que essa dicotomia está entranhada no próprio discurso criminal, sendo, por isso passível de ser historiada. A distinção, ainda que artificial - pois decorrente de esforços retóricos dos articuladores da doutrina penal -, serviu como estratégia, para a defesa da implantação de certos institutos penais.

Os que não são favoráveis à utilização desse binômio como uma categoria heurística afirmam que havia incongruências nessa divisão. Por exemplo, podese verificar, no discurso dito positivista, vários preceitos próprios do que se convencionou como Escola clássica, o que faria essa classificação perder a razão de ser. As premissas dessas críticas são corretas, realmente é possível enxergar várias contradições, nos argumentos dos penalistas, no que diz respeito a esse tema. Entretanto, isso não torna inviável a utilização de tal distinção, na história do direito penal, desde que se tome a mesma com a função de oferecer modelos, tipos ideais, para a melhor compreensão do discurso criminal. Isso, porque a distinção está inserida nas próprias fontes doutrinárias, objeto da pesquisa histórica jurídico-penal, e por isso assumi-la significa tomar por base o seu conteúdo, como categoria interpretativa ${ }^{66}$.

Mas o que realmente pode ser entendido acerca dessa disputa entre liberalismo penal clássico e positivismo criminológico, por meio da metaforologia, diz respeito aos postulados metafóricos assumidos por essas vertentes, que não anulam uns aos outros, em caso de divergências. Isso, porque metáforas absolutas não se anulam reciprocamente ${ }^{67}$, já que, em razão de sua

66 SONTAG, 2014, p. 99.

67 BLUMENBERG, 2013, p. 124. 
plasticidade, podem coexistir, mesmo quando isso representar, aparentemente, um enorme paradoxo. Essencialmente, não há contradições definitivas entre metáforas, apenas entre conceitos.

Por essa razão, podemos verificar os postulados representativos dos referenciais clássico e positivista - os quais são, na verdade, metáforas absolutas serem representados, concomitantemente, por meio de conceitos contraditórios, no discurso penal. Para elucidar melhor essa possibilidade, iremos nos resumir aos ideais de livre-arbítrio e determinismo, que são típicos da disputa entre as escolas. Ambos os postulados estão presentes no discurso penal há muito tempo: o primeiro pode ser compreendido como um dos motores da estruturação do direito penal ${ }^{68}$, enquanto que o segundo ganhou força com a modernidade, a partir do positivismo científico. Ambos são metafóricos, pois não se pode conceituar o que seria a liberdade - como já ensinara Immanuel Kant -, nem tampouco o determinismo no agir. A utilização dessas referências imanentes se dá por meio de conceitos jurídico-penais contingentes: dolo, culpabilidade, modelo de homem médio, potencial consciência de ilicitude, entre tantas outras categorias que, na verdade, são tão-somente conceitos aproximativos que vão se amoldando às metáforas absolutas, as quais sempre servem de guia para o sistema punitivo.

Não é nenhuma novidade a identificação de uma compatibilização desses ideais de livre-arbítrio e determinismo nas práticas penais. A consolidação de um direito penal resultante da combinação de preceitos clássicos e positivistas é uma característica geral, nas legislações criminais do século XX. Sobre o tema, Vera Regina Pereira de Andrade lembrou que "se esta convivência é possível, é porque o antagonismo escolar é mais aparente do que real; ou melhor, é porque se dissolve na prática do controle penal, a luta teórica entre as escolas que, consequentemente, não se explica nos limites de seus elementos gnoseológicos internos"69. Talvez a compreensão dos motivos determinantes, para a inexistência de conflitos entre os postulados, seja bem demonstrada utilizandose a metaforologia. De fato, os elementos gnoseológicos internos, aqueles mais profundamente sedimentados no discurso penal, não são colidentes entre si, exatamente porque são metáforas absolutas. Isso significa que eles não possuem conteúdo definido, que devem ser complementados indiretamente por conceitos paralelos. Assim, ainda que esses desdobramentos, sob a forma de conceitos complementares, sejam contraditórios entre si, a necessidade de manutenção das bases do discurso jurídico-penal, dos seus postulados metafóricos, acabaria por justificar esses paradoxos.

68 BRANDÃO, 2004, p. 109.

69 ANDRADE, 2013, p. 73. 
Com essa observação, fica mais compreensível o aparecimento histórico de conceitos tão contraditórios, como por exemplo a ideia de livre-arbítrio relativo, propugnada por Tobias Barreto. Com base na filosofia monista, e numa clara tentativa de conciliar os postulados positivistas com o ideal liberal, o autor sergipano defendia que "a liberdade humana é um fato da ordem natural, que tem a sua lei, porém não se deixa explicar mecanicamente"70. Aliás, muitos juristas empreenderam esforços para justificar uma aproximação entre positivismo e classicismo ${ }^{71}$. Até mesmo grandes defensores do positivismo, como João Vieira de Araújo, em certos momentos, chegaram a abrir mão de princípios caros a esse ideário, transacionando com posicionamentos típicos da escola clássica - visando sobretudo à manutenção ou implantação de outros institutos positivistas, que entendiam serem mais importantes ${ }^{72}$.

A partir da década de 30, o debate entre as escolas foi atenuado, com a incorporação de alguns preceitos positivistas menos radicais, sem que se inviabilizasse politicamente a sua implementação legislativa ${ }^{73}$. Contudo, isso não significa que os postulados metafóricos do livre-arbítrio e determinismo foram superados, pois ambos continuaram presentes, como fundamentos do discurso criminal. $\mathrm{O}$ que ocorreu foi uma modificação discursiva, pois a linguagem jurídica foi substancialmente alterada - por meio do advento do tecnicismo jurídico e da ideologia da defesa social -, de modo a se facilitar a criação de novos conceitos, para dialogar com as mesmas metáforas absolutas. Em outras palavras, a doutrina criminal passou a evitar a discussão direta dos postulados metafóricos, talvez em razão da percepção de que ambas não seriam passíveis de uma definição rigorosa - pois se situam em uma zona de não conceitualidade. Entretanto, persistiu com os mesmos fundamentos míticos, valendo-se da criação de conceitos neutros, os quais cumpriam melhor com a função retórica de veracidade aparente, por serem revestidos de cientificidade ${ }^{74}$.

Podemos ilustrar essas alegações com dois fenômenos marcantes, na doutrina penal. O primeiro deles é a construção de uma ideia jurídica de determinismo, por meio da conceituação de periculosidade - também chamada de perigosidade ou temibilidade. Trata-se de uma saída encontrada, para a fundamentação da responsabilidade criminal, evitando-se a discussão interminável sobre o abstrato e intrincado tema da liberdade de agir. Jimenez de Asúa admite essa estratégia, claramente, tendo afirmado que "a noção do estado perigoso é a fórmula moderna com que se trata de substituir, em matéria de responsabilidade criminal, os velhos e infecundos conceitos da imputabilidade

70 BARRETO, 1977, p. 318. Para maiores detalhes, vide: SANTOS, 2015.

71 FREITAS, 2002, p. 325-338.

72 SONTAG, 2014.

73 PRANDO, 2013, p. 91.

74 CASTRO JR., 2009, p. 88-89. 
moral e do livre arbitrio"75. Também Anibal Bruno, em uma longa explicação histórica, deixa evidente que o conceito de periculosidade é, na verdade, uma definição jurídica, resultante dos dilemas entre os postulados positivistas do determinismo, confrontados com a estrutura do direito penal clássico ${ }^{76}$. Ainda hoje, o conceito de periculosidade representa uma ferramenta de interpretação bastante utilizada, no sistema punitivo brasileiro, para a fundamentação da aplicação do direito penal, seja de forma expressa, seja de forma velada, escamoteada na retorica das decisões judiciais.

Caberia, aqui, uma ponderação interessante. A periculosidade apresenta dificuldades enormes de conceitualização, a ponto de ser justa a indagação sobre a sua natureza, se seria de fato um conceito ou uma metáfora absoluta. No primeiro cenário, caso se entenda a periculosidade como sendo um conceito, a definição jurídica teria por função moldar uma semântica específica, para a ideia de determinismo. No outro panorama, acreditando-se que seria uma metáfora absoluta, a modificação terminológica não significaria uma definição de significado, simplesmente teria se passado a chamar o determinismo, no agir criminal, de perigosidade. Em ambas as situações, o discurso criminal, ao utilizar o termo periculosidade, cumpriria com o papel estratégico, de desviar a atenção das fragilidades de uma fundamentação do direito em algo oco, uma imagem metafórica ${ }^{77}$. Para destrinchar tal questionamento seria necessária uma observação mais cuidadosa, que não caberia nos contornos desse trabalho. De toda forma, resta demonstrado a utilidade da metaforologia, para a análise do tema.

Outro fenômeno que ilustra a aproximação das posturas positivista e clássica é decorrente da adoção, pelo Código Penal de 1940, do sistema dualista de penas, também chamado de duplo binário. Trata-se da manutenção concomitante de pena e medida de segurança, consequência da preservação dos fundamentos representativos de quadrantes distintos do pensamento penal, a responsabilidade moral e culpabilidade - que seriam decorrentes do livrearbítrio - e a periculosidade - resultante da ideia de determinismo no agir. Sobre isso, Moacyr Benedicto de Souza afirmou que "tal concepção não representa, na verdade, mais que uma atitude conciliatória entre escolas. Os clássicos, partidários do livre arbítrio como fundamento da responsabilidade moral, colocam o doente mental à margem de qualquer sanção, enquanto que os positivistas, negando a autonomia da vontade humana e firmando-se na responsabilidade social,

75 ASÚA, 1933, p. 29.

76 BRUNO, 1977, p. 11-39.

77 Tal preocupação foi uma constante, no paradigma do tecnicismo jurídico, linha de pensamento que se preocupava com a efetividade jurídica dos institutos e, por isso, era avessa às grandes retóricas, muito comuns nos embates entre as escolas penais pretéritas (SONTAG, 2009, p. 7476). 
entendem que as sanções penais devem atingir todos os indivíduos que venham a delinquir"78. Trata-se de um entendimento entre conceitos contraditórios, com vistas à manutenção dos fundamentos metafóricos do sistema punitivo. Somente com a reforma penal de 1984, o dualismo foi substituído, adotandose a sistemática unificada vicariante, segundo a qual aplica-se somente a pena - que pode ser atenuada, em razão de semi-imputabilidade - ou a medida de segurança - para inimputáveis.

\section{REFERÊNCIAS}

ANDRADE, Vera Regina Pereira. A Ilusão de segurança jurídica: do controle da violência a violência do controle penal, $2^{a} \mathrm{ed}$. Porto Alegre: Livraria do Advogado, 2003.

ASÚA, Jimenez de. O Estado perigoso: nova fórmula para o tratamento penal e preventivo. São Paulo: Edições e Publicações Brasil, 1933.

BARRETO, Tobias. Glosas heterodoxas a um dos motes do dia: ou variações anti-sociológicas. Estudos de filosofia. São Paulo: Grijalbo, 1977.

BLUMENBERG, Hans. The Legitimacy of the modern age. Cambridge: The MIT Press, 1999. 2010.

. Paradigms for a metaphorology. New York: Cornell University Press,

Teoria da não conceitualidade. Belo Horizonte: UFMG, 2013.

BRANDÃO, Cláudio. Posição da culpabilidade na dogmática penal. Revista de estudos criminais, $\mathbf{n}^{\mathbf{0}}$ 16. Porto Alegre: PUCRS/!TEC, 2004.

BRUNO, Aníbal. Perigosidade criminal e medidas de segurança. Rio de Janeiro: Editora Rio, 1977.

CASSIRER, Ernst. Linguagem e mito: uma contribuição ao problema dos nomes dos deuses. São Paulo: Perspectiva, 1972.

CASTRO JR., Torquato. A Pragmática das nulidades e a teoria do ato jurídico inexistente. São Paulo: Noeses, 2009.

DA MAIA, Alexandre. Ontologia jurídica: o problema de sua fixação teórica com relação ao garantismo jurídico. Porto Alegre: Livraria do advogado, 2000.

O Direito subjetivo como imagem: da invisibilização dos paradoxos na teoria dos sistemas à interação e às situações comunicativas na pragmática normativo-comunicacional de Tercio Sampaio Ferraz Jr. ADEODATO, João

78 SOUZA, 1979, p. 35. 
Maurício; BITTAR, Eduardo C. B. Filosofia e teoria geral do direito: homenagem a Tercio Sampaio Ferraz Junior. São Paulo: Quartier Latin, 2011.

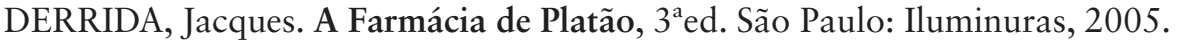

FOUCAULT, Michel. L’Arqueologie du savoir. Paris: Gallimard, 1969. Surveiller et punir: naissance de la prison. Paris: Gallimard, 1975. A Verdade e as formas jurídicas, $3^{\mathrm{a}} \mathrm{ed}$. Rio de Janeiro: Nau, 2005. . A Ordem do discurso, 23ª ed. São Paulo: Loyola, 2013.

FREITAS, Ricardo. As Razões do positivismo penal no Brasil. Rio de Janeiro: Lumen Juris, 2002.

GADAMER, Hans-Georg. Teoria da história e linguagem: uma réplica de HansGeorg Gadamer. KOSELLECK, Reinhart. Estratos do tempo: estudos sobre história. Rio de Janeiro: Contraponto, 2014.

HART, Herbert. O Conceito de direito, 5ªed. Lisboa: Fundação Calouste Gulbekian, 2007.

HARTOG, François. Sobre la noción de régimen de historicidade: entrevista con François Hartog. DOSSE, François et ali (orgs.). Historicidades. Buenos Aires: Waldhuter, 2010.

HEIDENREICH, Felix. Political aspects in Hans Blumenberg's philosophy. Revista de Filosofia Aurora, v. 27, n. 41. Curitiba: PUC/PR, 2015.

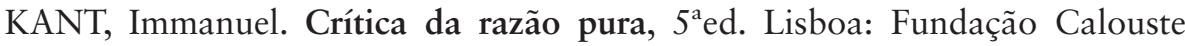
Gulbekian, 2001.

KOSELLECK, Reinhart. Futuro passado: contribuição à semântica dos tempos históricos. Rio de Janeiro: Contraponto, 2006.

LIMA, Luiz Costa. Introdução. BLUMENBERG, Hans. Teoria da não conceitualidade. Belo Horizonte: UFMG, 2013.

LIMA, Pedro Parini Marques de. A Metáfora do direito e a retórica da ironia no pensamento jurídico. Tese de doutorado. Recife: Universidade Federal de Pernambuco, 2013b.

LÖWITH, Karl. O Sentido da história. Lisboa: Edições 70, 1991.

NIETZSCHE, Friedrich. O Nascimento da tragédia: ou helenismo e pessimismo, $2^{a}$ ed. São Paulo: Companhia das Letras, 1999.

. Verdade e mentira no sentido extramoral. Comum, v. 6, n. 17. Rio de Janeiro: FACHA, 2001. 
. Aurora: reflexões sobre os preconceitos morais. São Paulo: Companhia das letras, 2004.

OLIVECRONA, Karl. Lenguaje jurídico y realidade. Mexico: Fontamara, 2010.

PRANDO, Camila Cardoso de Mello. O Saber dos juristas e o controle penal: o debate doutrinário na Revista de Direito Penal (1933-1940) e a construção da legitimidade pela defesa social. Rio de Janeiro: Revan, 2013.

ROSS, Alf. Tû-Tû. São Paulo: Quartier Latin, 2004.

SALDANHA, Nelson. Criatividade e metáforas em ciências sociais.

Filosofia, povos, ruínas: páginas para uma filosofia da história. Rio de Janeiro: Calibán, 2002.

SANTOS, Hugo Leonardo R. Tobias Barreto e o positivismo penal.

Estudos críticos de criminologia e direito penal. Rio de Janeiro: Lumen Juris, 2015.

SCHMITT, Carl. Teologia política. Belo Horizonte: Del Rey, 2006.

SONTAG, Ricardo. Código e técnica: a reforma penal brasileira de 1940, tecnização da legislação e atitude técnica diante da lei em Nelson Hungria. Dissertação de Mestrado. Florianópolis: UFSC, 2009.

. Código criminológico? Ciência jurídica e codificação penal no Brasil (1888-1899). Rio de Janeiro: Revan, 2014.

SOUZA, Moacyr Benedicto de. O Problema da unificação da pena e da medida de segurança. São Paulo: José Bushatsky, 1979.

WEBER, Max. A Ética protestante e o espírito do capitalismo. São Paulo: Companhia das letras, 2004.

WITTGENSTEIN, Ludwig. Tractatus logico-philosophicus. Paris: Gallimard, 1993.

Recebido em: 04/02/2019.

Aprovado em: 07/08/2019. 


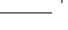

